\title{
O CLIMA URBANO EM TEODORO SAMPAIO/SP: EPISÓDIOS DE VERÃO
}

\author{
Simone Scatolon Menotti Viana9 \\ Margarete Cristiane de Costa Trindade Amorim
}

\begin{abstract}
RESUMO
As cidades, ao se desenvolverem, assumem o papel de agente modificador do meio natural. Dentre todas as transformações ocorridas no ambiente urbano, uma que merece especial atenção é a modificação dos elementos do clima. Este trabalho visou compreender até que ponto o tamanho de uma cidade pode comprometer as condições climáticas e gerar um clima urbano específico. 0 objetivo principal foi verificar as diferenças existentes entre a temperatura, a umidade relativa e a direção do vento em pontos com uso e ocupação do solo diferenciados. Assim, foram realizadas leituras simultâneas dos psicrômetros em sete pontos, sendo seis inseridos na malha urbana e um na área rural próxima, às $7 \mathrm{~h}, 9 \mathrm{~h}, 15 \mathrm{~h}$ e $21 \mathrm{~h}$, por 13 dias de Janeiro de 2005, dias representativos do verão - quente e chuvoso. Esta pesquisa concluiu que Teodoro Sampaio, com 15.922 habitantes na área urbana, apresenta características de um clima específico e, durante os dias representativos de verão, ficou comprovada a formação de ilhas de calor e de frescor.
\end{abstract}

Palavras-chave: clima urbano, ilhas de calor, Teodoro Sampaio, temperatura, umidade relativa.

\section{ABSTRACT}

As cities develop they take on the role of modifying agent of the natural environment. Among all the transformations that have occurred in the urban environment, one that deserves special attention is the modification of the climatic elements. This study aimed to understand up to what point the size of a city can compromise climatic conditions and generate a specific urban climate. The main objective was to verify the existing differences between temperature, relative humidity and wind direction in places with differentiated soil use and occupation. Thus, simultaneous readings of psychrometers were made at seven points, six within the urban network and one in a rural area at 7:00AM, 9:00AM, 3:00PM and 9:00PM, for 13 days in January 2005, days representative of the summer - hot and rainy. This study concluded that Teodoro Sampaio, with 15,922 inhabitants in the urban area, shows characteristics of a specific climate,

\footnotetext{
${ }^{9}$ Profa. MS. pelo curso de Pós-Graduação em Geografia da FCT - UNESP - Presidente Prudente/SP (simoneviana10@yahoo.com.br).
} 
and during the days that represented the summer, the formation of pockets of heat and freshness was proven.

Key-words: urban climate, urban heat island, Teodoro Sampaio, temperature, relative humidity.

\section{INTRODUÇÃO}

As cidades podem ser entendidas como organizações excelentemente humanas, nas quais o homem atua com toda a sua plenitude, transformando a natureza em prol de suas necessidades. Diante de tamanha intervenção nos aspectos ecológicos e, principalmente, na vida das pessoas, surge a necessidade de estudos que evidenciem a qualidade do ambiente urbano.

Os estudos sobre o ambiente urbano se intensificaram a partir do término da Segunda Guerra Mundial, e, nas últimas décadas, vem se traduzindo em fóruns e conferências mundiais. Estes possuem o intuito de formular propostas e metas para promover o desenvolvimento sustentável, conservar as reservas destinadas às gerações futuras, e defender as que estão em produção, contra a exploração imprevidente.

Dentre todas as transformações ocorridas no ambiente urbano, uma que merece especial atenção é a modificação dos elementos do clima (temperatura, umidade, ventos, precipitação), que afetam diretamente a vida de todos os habitantes. Assim, surge a necessidade de estudos que privilegiem a análise do comportamento da atmosfera urbana.

"O clima constitui-se numa das dimensões do ambiente urbano e seu estudo tem oferecido importantes contribuições ao equacionamento da questão ambiental nas cidades. As condições climáticas destas áreas, entendidas como clima urbano, são derivadas da alteração da paisagem natural e da sua substituição por um ambiente construído, palco de intensas atividades humanas" (MENDONÇA, 2003, p. 93).

O clima urbano é específico para cada ambiente urbanizado, e este consiste na modificação dos elementos climáticos, como a temperatura, a umidade relativa e a direção dos ventos. Para Monteiro (1990a), o clima urbano pode ser entendido como um sistema complexo, aberto, adaptativo que, ao receber energia do ambiente maior no qual se insere, transforma-o substancialmente, a ponto de gerar uma produção exportada ao ambiente. A síntese de Landsberg coloca o seguinte:

"a) o clima urbano é a modificação substancial de um clima local, não sendo possível ainda decidir sobre o ponto de concentração populacional ou densidade de edificações em que essa notável mudança principia; b) admite-se que o desenvolvimento urbano tende a acentuar ou eliminar as diferenças causadas pela posição ou sítio; c) da comparação entre a cidade e o circundante, emergiram os seguintes fatos fundamentais:1) a cidade modifica o clima através de alterações em superfície; 2 ) a cidade produz um aumento de calor, complementado por modificações na ventilação, na umidade e até nas precipitações, que tendem a ser mais acentuadas; 3) a maior influência manifesta-se através da alteração na própria composição da atmosfera, atingindo condições adversas na maioria dos casos. A poluição atmosférica representa, no presente, o problema básico da climatologia das modernas cidades industrializadas". (LANDSBERG, apud MONTEIRO,1976, p.57). 
Os estudos sobre clima urbano realizados até o momento têm dado maior relevância a cidades de grande porte, supostamente pelo maior comprometimento da qualidade de vida e pelo agravamento dos problemas ambientais. No Brasil, há poucos trabalhos realizados em cidades de pequeno e de médio portes, embora, em nível internacional, exista maior número de trabalhos relacionados à investigação de clima urbano em cidades de pequeno porte.

Considerando-se a carência de estudos sobre a qualidade do ambiente urbano de pequeno porte no Brasil, e a necessidade de se realizar pesquisas que se referem à qualidade ambiental necessária para o desenvolvimento da vida humana, foi proposto o estudo do clima urbano de Teodoro Sampaio/SP. Este trabalho visou compreender até que ponto o tamanho de uma cidade pode comprometer as condições climáticas e gerar um clima urbano específico, e qual a magnitude do fenômeno, pensando-se nas analogias internas entre os atributos geoecológicos do sítio, a morfologia e as funções urbanas, colaborando, assim, na solução dos problemas enfrentados no meio urbano.

O estudo teve como objetivo principal verificar e compreender as diferenças existentes entre a temperatura, a umidade relativa e a direção do vento em usos e ocupação do solo diferenciados, permitindo a compreensão dos fenômenos, bem como, a identificação de anomalias e suas magnitudes durante dias representativos do verão, numa cidade de pequeno porte.

Teodoro Sampaio está localizada a $22^{\circ} 53^{\prime}$ e $25^{\prime \prime}$ de latitude sul e a $52^{\circ} 16^{\prime} 75^{\prime \prime}$ de longitude oeste, distante $112 \mathrm{Km}$ de Presidente Prudente e 672 $\mathrm{Km}$ da capital paulista (Figura 1). A cidade de Teodoro Sampaio, como muitas outras da região oeste do Estado de São Paulo, teve sua origem e crescimento inicial em virtude da construção da Estrada de Ferro Sorocabana. Tem como aspectos sociais as seguintes características: a população absoluta em 2000 é de 20.003 habitantes, de acordo com os dados do censo demográfico realizado pelo IBGE. A população urbana é de 15.922 e a rural de 4.081 habitantes. A densidade demográfica do município de Teodoro Sampaio é de $12,8 \mathrm{Hab} / \mathrm{km}^{2}$; assim, ele pode ser considerado de baixa densidade demográfica. Sua economia está baseada na criação de gado bovino de corte e leiteiro, além da atividade comercial.

A partir dos dados apresentados, é possível identificar-se a cidade como sendo de pequeno porte e com características típicas de uma cidade do interior, ou seja, baixa densidade populacional, ausência de industrialização, economia voltada para a agropecuária e atividade comercial para a subsistência local. Embora, com típica aparência de cidade do interior, Teodoro Sampaio já apresenta características diferenciadas de uso e ocupação do solo.

A ocupação do solo na cidade de Teodoro Sampaio se deu a partir da estação férrea em direção ao que hoje é o centro comercial da cidade, no sentido oeste; observa-se um processo de empobrecimento da área próxima à estação, que hoje está desativada. Nas porções norte, leste e sul há a presença de muitas casas de madeira ou de alvenaria semi acabadas, terrenos baldios e sem arruamento pavimentado.

$\mathrm{Na}$ porção oeste e central de Teodoro Sampaio localiza-se a área comercial, e que gerou o incentivo de investimentos em infra-estrutura e melhorias locais, como o arruamento asfaltado, e propiciou, também, os investimentos imobiliários, como, a abertura de um conjunto habitacional.

A cidade não possui plano diretor e nota-se que não há, ainda, um planejamento urbano adequado. A malha urbana acaba expandindo-se em áreas 
impróprias, como no caso do conjunto habitacional conhecido como COHABCRIS, que ocasionou o assoreamento do Ribeirão Cuiabá, devido à retirada da cobertura vegetal para a construção das casas.

\section{PROCEDIMENTOS METODOLÓGICOS}

Neste trabalho foram utilizadas as propostas de Monteiro (1976 e 1990), como método de análise, que formalizam uma estrutura teórica e metodológica para a compreensão do clima urbano. Assim, este método tem como base a perspectiva sistêmica para hierarquizar as relações entre o ambiente urbano e as alterações ocorridas nos elementos climáticos sobre a cidade, definindo assim o Sistema Clima Urbano (S.C.U.).

Para o levantamento de campo foram realizadas coletas de dados com mini-abrigos meteorológicos. Os pontos foram selecionados a partir das características do relevo, da declividade e da hidrologia, sendo estas associadas ao tipo de uso e ocupação do solo.

A ocupação da malha urbana foi dividida em seis classes:

- área densamente construída, com vegetação arbórea ausente e pavimentação nas ruas;

- área densamente construída, com vegetação arbórea de grande porte, em abundância, e pavimentação nas ruas;

- área densamente construída, com vegetação arbórea de médio porte, esparsa, e ruas parcialmente pavimentadas;

- área densamente construída, com dois pavimentos, vegetação arbórea de médio porte e pavimentação nas ruas;

- construções esparsas, gramados e vegetação arbórea de grande porte, em abundância, e ruas sem pavimentação;

- construções esparsas, gramados e vegetação arbórea esparsa à ausente e ruas sem pavimentação.

As áreas densamente construídas se encontram localizadas próximas do centro comercial da cidade. Estas áreas se distinguem pelo tipo de vegetação que possuem. As áreas menos construídas estão mais afastadas do centro e possuem menos vegetação.

Quanto ao tipo de uso do solo, a cidade se organiza, principalmente, em comercial e residencial. A partir da caracterização do uso e da ocupação do solo, associada ao tipo de relevo e à presença de vegetação, foi possível escolher os pontos de coletas de dados. São eles:

- Vila São Paulo - área de construções esparsas, gramados e vegetação de grande porte em abundância. O uso do solo destina-se exclusivamente ao residencial;

- Prefeitura - área densamente construída, com vegetação arbórea ausente. O uso do solo é comercial;

- Odilon Ferreira - área densamente construída, com vegetação arbórea de grande porte, em abundância. O uso do solo é misto, sendo, ao mesmo tempo, comercial e residencial;

- Vila Furlan - área densamente construída, com vegetação arbórea de médio porte. O uso do solo é misto, tendo o residencial maior predominância; 
- Vila Minas Gerais - área densamente construída, com dois pavimentos, e vegetação arbórea de médio porte. Uso do solo exclusivamente residencial;

- Estação - área de construções esparsas, gramados e vegetação arbórea esparsa ou ausente. Uso do solo residencial.

- Rio Paranapanema - área de vegetação esparsa e gramado, próxima ao Rio Paranapanema. O uso do solo destina-se às atividades rurais, como a pecuária e a agricultura.

Os mini-abrigos meteorológicos foram constituídos de psicrômetros, ou seja, pares de termômetros (bulbo seco e bulbo úmido) para medidas de temperatura e de umidade relativa do ar, e fita de cetim, fixada na parte inferior do mini-abrigo e utilizada para indicar a direção do vento. A velocidade do vento foi estimada a partir da "Escala de Beaufort", possibilitando que a mesma fosse definida sem auxílio instrumental. Os mini-abrigos foram construídos de madeira, com paredes duplas perfuradas para permitir a livre circulação do ar; eles foram encaixados em uma haste com $1,50 \mathrm{~m}$ do solo para que os termômetros não sofressem influência direta da radiação terrestre e um suporte de madeira para encaixar os termômetros no interior do mini-abrigo. Esta metodologia foi utilizada por Sezerino e Monteiro (1990).

As leituras foram realizadas simultaneamente em sete pontos, sendo seis inseridos na malha urbana e um na área rural próxima, às $7 \mathrm{~h}, 9 \mathrm{~h}, 15 \mathrm{~h}$ e $21 \mathrm{~h}$, durante 13 dias de janeiro de 2005 (17/01 a 29/01), dias representativos do verão - quente e chuvoso.

Ao término dos trabalhos de campo, as leituras coletadas foram digitadas e organizadas em tabelas, na planilha eletrônica Excel ${ }^{10}$. Com a utilização do Software Surfer for Windows, os dados de temperatura do ar foram espacializados por meio da geração de isotermas para melhor visualização dos resultados obtidos, o que permitiu construir um perfil das condições térmicas e higrométricas intra-urbanas. Para a melhor compreensão do comportamento da temperatura foi realizada a análise dos sistemas atmosféricos regionais, através das cartas sinóticas de superfície e das imagens de satélite Góes, disponibilizadas diariamente no sítio da marinha do Brasil e no sítio do INPE ${ }^{11}$.

\section{O clima urbano em Teodoro Sampaio}

Os tipos de tempo atmosférico atuantes em Teodoro Sampaio devem ser analisados a partir da compreensão de como se desenvolve a circulação atmosférica no extremo Oeste Paulista. Quase todos os sistemas atmosféricos que atuam no continente sul americano contribuem para o estabelecimento e definição do tempo e do clima na região em questão.

No Extremo Oeste Paulista há uma alternância de massas de ar tropicais e polares, sendo de grande importância a participação da Frente Polar Atlântica na formação das chuvas, principalmente na primavera e no verão, quando são freqüentes e intensas, causando períodos de aumento na umidade. No outono e no inverno, os sistemas estabilizadores causam diminuição das chuvas, provocando um período mais seco. (BARRIOS e SANT'ANNA NETO, 1996).

\footnotetext{
${ }^{10}$ Excel - é marca registrada da Microsoft Corporation.

${ }^{11}$ www.mar.mil.br; www.cptec.inpe.br.
} 
Durante o período da pesquisa houve a entrada de três sistemas frontais, ocasionando chuva em quase $70 \%$ dos dias estudados. No dia 17/01 houve a passagem do primeiro sistema frontal pelo oceano, provocando a formação de muitas nuvens e chuva intensa. Do dia 18 a 21/01 houve o predomínio de um sistema de baixa pressão que, combinado com elevados valores de umidade e temperatura do ar, ocasionaram nuvens, algumas com grande desenvolvimento vertical.

Nos dias 22/01 e 23/01 um novo sistema frontal avançou pelo oceano Atlântico, ocasionando chuva de fraca intensidade na região.

Nos dias 24/01 e 25/01, na região sudeste, a nebulosidade aumentou, devido à atuação da Zona de Convergência do Atlântico Sul (ZCAS).

No dia 26/01 havia atuação de massa de ar Tropical Continental e, no início da noite, a chegada de um sistema frontal.

No dia 27/01 houve a chegada de um sistema frontal à região sudeste. Este sistema provocou muitas áreas de instabilidades, ocasionando chuva. Do dia 28 a 30/01 houve o predomínio de uma Massa de ar Polar Atlântica no oceano, e, no continente, a atuação de um sistema de baixa pressão.

No geral, a entrada de sistemas frontais, associados aos elevados índices de umidade e temperatura, provocou precipitação. A chuva proporcionou ligeira queda nas temperaturas, mas, no decorrer da tarde, com algumas aberturas de sol, esta se elevou, ocasionando desconforto térmico resultante do calor e da alta umidade devido ao intenso processo de evaporação.

A seguir segue caracterização dos elementos climáticos em cada horário pesquisado, bem como, a sua distribuição na malha urbana de Teodoro Sampaio/SP.

\section{Caracterização dos elementos climáticos às 7h}

Às 7h, a distribuição da temperatura e umidade relativa foram as seguintes: Odilon Ferreira e Prefeitura apresentaram-se mais quentes e secos, embora o ponto localizado próximo à Prefeitura tenha apresentado dias de umidade relativa superior ao ponto localizado nas proximidades da Rua Odilon Ferreira. O ponto Vila Minas Gerais esteve em situação intermediária (Figura 1).

Os pontos com menores temperaturas foram Vila São Paulo, Vila Furlan e Estação. A Vila São Paulo esteve sempre com a umidade relativa do ar elevada, mas a Estação, embora com menores temperaturas, apresentou dias com baixas taxas de umidade relativa.

A amplitude térmica entre os pontos se mostrou de fraca magnitude, entre $1^{\circ} \mathrm{C}$ e $2^{\circ} \mathrm{C}$. A amplitude higrométrica esteve entre $7 \%$ e $24 \%$. As maiores amplitudes térmicas foram observadas nos dias 21/01, 23/01 e 26/01, sendo respectivamente $2,1^{\circ} \mathrm{C}, 2^{\circ} \mathrm{C}$ e $2,2^{\circ} \mathrm{C}$. As maiores amplitudes higrométricas foram, também, observadas nestes dias, sendo $15 \%, 10,9 \%$ e $24 \%$. Estas amplitudes estão associadas ao aquecimento pré-frontal.

De acordo com García (1996), a magnitude da ilha de calor é definida a partir da diferença entre o ponto mais aquecido e o de menor temperatura. Ele propôs a seguinte classificação: $0^{\circ} \mathrm{C}$ a $2^{\circ} \mathrm{C}$ (fraca), $2^{\circ} \mathrm{C}$ a $4^{\circ} \mathrm{C}$ (moderada), $4^{\circ} \mathrm{C}$ a $6^{\circ} \mathrm{C}$ (forte) e acima de $6^{\circ} \mathrm{C}$ (muito forte).

Nos dias 21/01 e 23/01, o ponto Odilon Ferreira apresentou as maiores

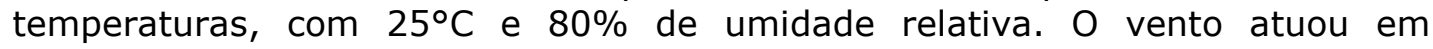
diferentes direções, sendo Sul e Oeste, com velocidade de 3,4 a 5,2 m/s. A 
direção do vento proporcionou dois comportamentos, sendo que o do quadrante Sul propiciou a propagação do calor em direção à Vila São Paulo, e o do quadrante Oeste, em direção à Vila Minas Gerais. Ambos os dias estavam em condições de aquecimento Pré-Frontal.

No dia 26/01, o ponto localizado próximo à Prefeitura apresentou a maior temperatura: $25^{\circ} \mathrm{C}$ com $70 \%$ de umidade relativa, ventos de Leste, com velocidade de 3,4 a 5,2 m/s. Este comportamento pode ser explicado a partir da direção e velocidade do vento, ou seja, provenientes de Leste, com velocidade elevada, provocaram um deslocamento da área mais quente e seca do ponto Odilon Ferreira para o ponto da Prefeitura, além de ter proporcionado a maior amplitude higrométrica entre os pontos, de $24 \%$. Além deste fato, houve uma homogeneização da temperatura entre os pontos Vila Furlan, Vila Minas Gerais e Estação.

Nos dias 17, 18, 19, 20, 22, 25, 27, 28 e 29, o ponto próximo ao Rio Paranapanema apresentou temperaturas elevadas e similares à área urbana. A umidade relativa não se comportou da mesma forma, pois no Rio Paranapanema esteve mais elevada que nas áreas urbanas. Desta forma, as altas temperaturas estão relacionadas às elevadas taxas de umidade relativa e, ainda, à presença de nebulosidade que provocou desconforto térmico, devido a grande quantidade de vapor d'água presente na atmosfera.

Nestes dias, os ventos predominaram do quadrante $\mathrm{N}$, mudando de direção apenas nos dias 28 e 29, para SE. A velocidade encontrou-se consideravelmente alta, chegando até $9,8 \mathrm{~m} / \mathrm{s}$. O vento mostrou-se muito presente sobre a calha do rio e suas proximidades. Com o distanciamento do rio, o vento modificava a sua direção e perdia velocidade.

As condições térmicas e higrométricas que se esboçaram às $7 \mathrm{~h}$ resultaram do comportamento estabelecido no dia anterior. Assim, verificou-se a capacidade da área urbana em armazenar calor e ainda devolver, nas primeiras horas do dia seguinte, o calor armazenado no dia anterior.

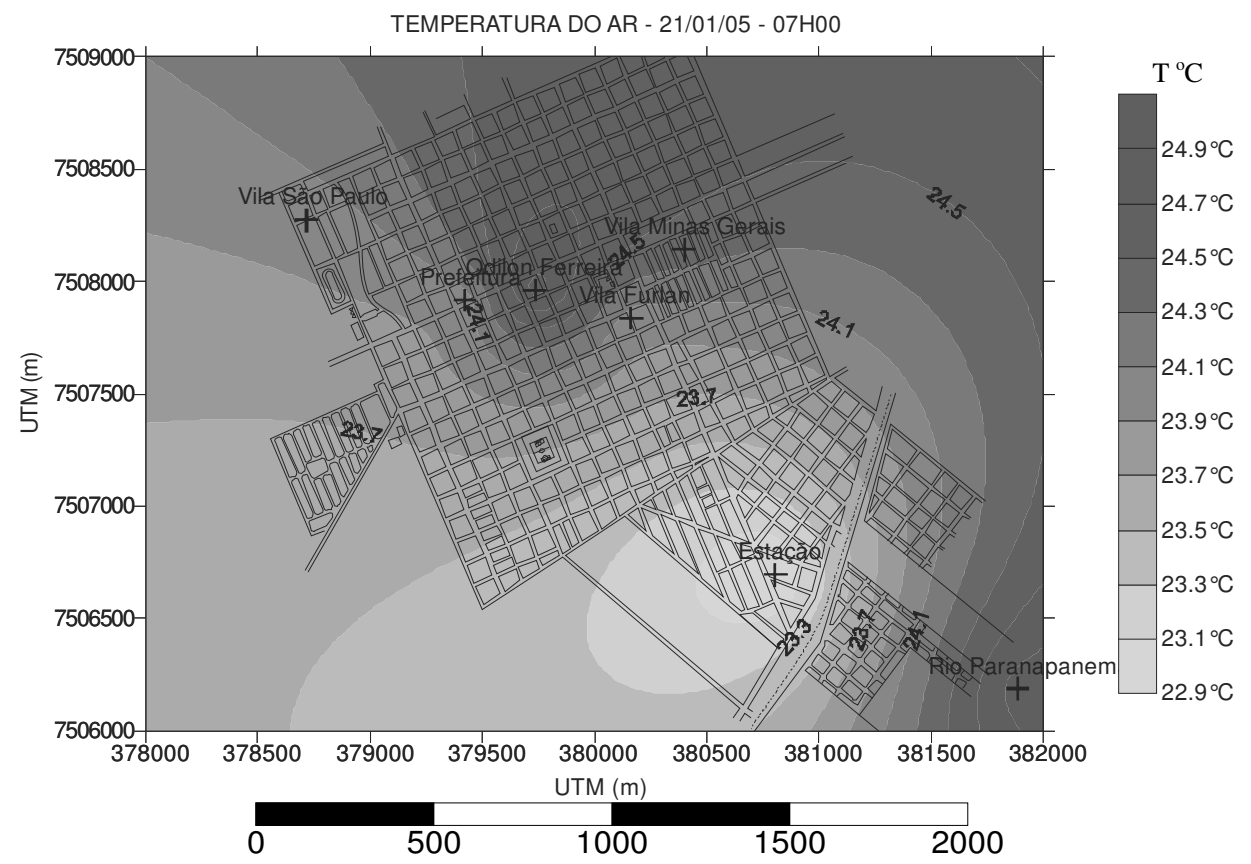

Figura 1: Isotermas às 7h (padrão predominante no horário) 


\section{Caracterização dos elementos climáticos às 9 h}

Às 9h, a configuração de temperatura e umidade relativa que se apresentou às $7 \mathrm{~h}$ perdeu intensidade ou desapareceu completamente. As áreas centrais da cidade (Odilon Ferreira e Prefeitura) deixaram de possuir as maiores temperaturas, embora a umidade relativa continuasse baixa, principalmente no Odilon Ferreira (Figura 2).

Neste horário, as áreas mais periféricas da malha urbana e o ponto rural adquiriram uma magnitude maior para a temperatura, e as taxas de umidade relativa declinaram. Isso ocorreu nos dias 17/01, 20/01, 22/01, 26/01, 27/01, 28/01, 29/01 (Rio Paranapanema), 18/01 e 23/01 (Estação) e 21/01 (Vila Minas). Cabe salientar ainda, que, em alguns destes dias a Vila São Paulo apresentou temperaturas intermediárias. Este comportamento ocorreu em decorrência do fato de que as áreas mais livres de construções ou do campo se aqueceram mais rapidamente, e começaram a devolver o calor para a atmosfera.

Nos dias citados acima, o ponto próximo ao Rio Paranapanema apresentou a seguinte configuração: temperatura em torno de $25^{\circ} \mathrm{C}$, com taxas de umidade relativa que variaram entre $80 \%$ a $90 \%$, ventos do quadrante $\mathrm{N}$, com velocidade que variou entre 5,3 à $7,4 \mathrm{~m} / \mathrm{s}$, e ainda presença de garoa e nebulosidade total. Na Estação, a temperatura esteve em torno de $25^{\circ} \mathrm{C}$, com umidade relativa acima de $90 \%$, ventos de Oeste e Sudeste, com velocidade entre 1,8 a $5,2 \mathrm{~m} / \mathrm{s}$.

As maiores amplitudes térmicas foram observadas nos dias $18 / 01,21 / 01$, $23 / 01,24 / 01$ e $25 / 01$. Os valores encontrados foram, respectivamente, os seguintes: $2,2^{\circ} \mathrm{C}, 3,9^{\circ} \mathrm{C}, 2,1^{\circ} \mathrm{C}, 2^{\circ} \mathrm{C}, 2,8^{\circ} \mathrm{C}$. As maiores amplitudes higrométricas se apresentaram nos seguintes dias 18/01 (13,2\%), 21/01 $(15 \%), 24 / 01(14,5 \%), 25 / 01$ (25\%), 26/01 (22,9\%) e 27/01 (22,1\%). As amplitudes térmicas e higrométricas apresentaram maiores magnitudes em comparação com as das 7h. De acordo com García (1996), a magnitude foi moderada (entre $2^{\circ}$ e $4^{\circ} \mathrm{C}$ ).

Nos dias acima citados, as condições sinóticas foram: atuação de uma Polar enfraquecida (18/01) e atuação da Tropical Continental (21/01, 23/01, 24/01 e 25/01), sendo que, nos dias 21 e 25, observaram-se condições de aquecimento pré-frontal.

No dia $21 / 01$, verificou-se a maior amplitude térmica $\left(3,9^{\circ} \mathrm{C}\right)$, e a Vila Minas Gerais foi o local mais aquecido. A temperatura observada foi de $30,8^{\circ} \mathrm{C}$, com $76,3 \%$ de umidade relativa, ventos de $\mathrm{S}$ com velocidade de 3,4 à $5,2 \mathrm{~m} / \mathrm{s}$ e céu parcialmente coberto.

As condições de temperatura e umidade relativa, às $9 \mathrm{~h}$, são conseqüências dos seguintes fatores: a) do armazenamento de calor desde as primeiras horas do dia nas áreas mais livres de construções e no campo, e que, neste horário, ele é mais facilmente devolvido para a atmosfera, fazendo com que estas áreas se apresentassem mais aquecidas que as áreas centrais da malha urbana; b) do efeito "sombra", ou seja, as áreas centrais, com maior número de construções e até mesmo de vegetação, impediram que os raios atingissem a superfície completamente e, assim, retardaram o armazenamento do calor. 


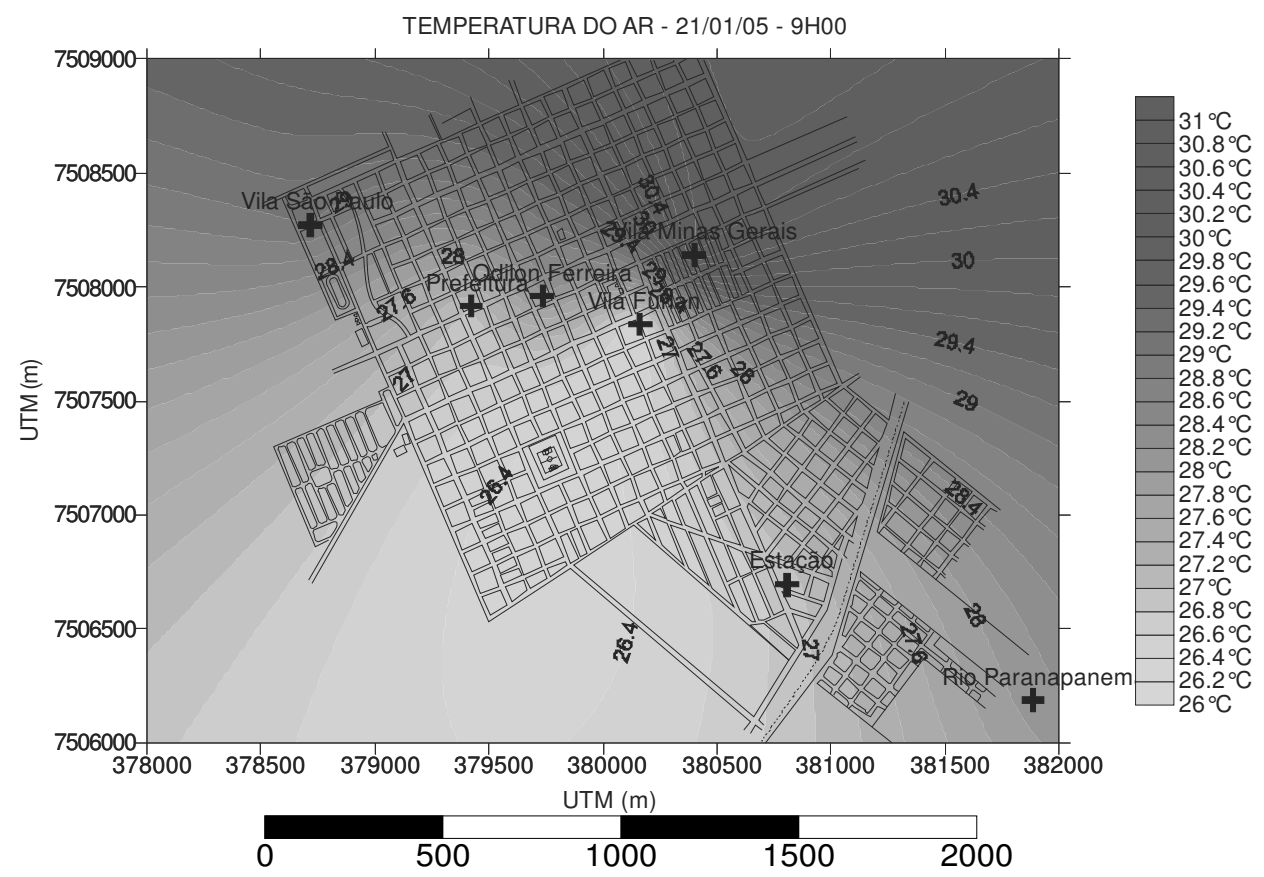

Figura 2: Isotermas às 9h (padrão predominante no horário)

\section{Caracterização dos elementos climáticos às 15h}

Às $15 \mathrm{~h}$, o comportamento que se apresentou no período da manhã ( $9 \mathrm{~h}$ ) se definiu e observaram-se as maiores magnitudes. No centro da cidade (Prefeitura), com alta densidade de construções, com pouca vegetação, as temperaturas declinaram com relação aos demais pontos. O ponto Odilon Ferreira (densamente construído e com vegetação arbórea) passou a ter temperaturas intermediárias (Figura 3).

No ponto rural, próximo ao Rio Paranapanema, área totalmente coberta por gramados e vegetação arbórea de esparsa a ausente, constataram-se temperaturas altas em 6 dias (18/01, 19/01, 23/01, 24/01, 26/01 e 28/01). A temperatura do ar esteve sempre acima dos $30^{\circ} \mathrm{C}$ e a umidade relativa entre $70 \%$ a $80 \%$, sendo que esta não se comportou de forma inversamente proporcional à temperatura, e as menores taxas foram observadas na cidade. 0 vento, nestes dias, predominou do quadrante Leste, com calmaria ( 0 a $1,7 \mathrm{~m} / \mathrm{s}$ de acordo com a escala de Beaufort) e, céu totalmente coberto por nuvens.

As maiores amplitudes térmicas encontradas foram: $18 / 01\left(5,4^{\circ} \mathrm{C}\right)$, $19 / 01\left(3,5^{\circ} \mathrm{C}\right), 21 / 01\left(3^{\circ} \mathrm{C}\right), 22 / 01\left(3,2^{\circ} \mathrm{C}\right), 23 / 01\left(3,4^{\circ} \mathrm{C}\right), 26 / 01\left(4,5^{\circ} \mathrm{C}\right)$, $28 / 01\left(2,4^{\circ} \mathrm{C}\right)$ e $29 / 01\left(4,2^{\circ} \mathrm{C}\right)$. As amplitudes higrométricas, também, estiveram elevadas, entre $20 \%$ a $40 \%$.

A maior amplitude térmica entre os pontos foi observada no dia 18/01, chegando a $5,4^{\circ} \mathrm{C}$, sendo o Rio Paranapanema o local mais aquecido, com $33,8^{\circ} \mathrm{C}, 74,3 \%$ de umidade relativa, vento de Sul, com baixa velocidade de 0 a $1,7 \mathrm{~m} / \mathrm{s}$.

Neste horário, as amplitudes térmicas ficaram entre $3^{\circ} \mathrm{C}$ e $5^{\circ} \mathrm{C}$, assim sendo de moderada a forte. 
As menores temperaturas foram observadas nas áreas com densidade de construções moderadas, com vegetação e sem a presença de ruas pavimentadas, demonstrando, assim, a importância da vegetação para a diminuição do calor. Este comportamento foi observado nos pontos Vila Furlan e Estação.

A menor amplitude observada entre os pontos foi de $0,6^{\circ} \mathrm{C}$ no dia $17 / 01$; choveu durante todo este dia, e a menor temperatura foi observada na Vila Furlan, com presença de vegetação e ausência de ruas com asfalto. Este valor pode ser atribuído à passagem de um sistema Frontal.

O comportamento térmico e higrométrico que se apresentou foi conseqüência do fato do ponto próximo ao Rio Paranapanema tender a ser mais aquecido, devido ao intenso processo de evaporação e condensação, que provocou a formação de nuvens, assim fazendo com o calor armazenado na molécula de água fosse liberado, produzindo aumento da temperatura. Este fenômeno foi intensificado nos dias em que ocorreram chuvas mais fortes no período da manhã, associado à incidência direta dos raios solares próximo do meio dia.

Nas áreas urbanas densamente construídas (Odilon Ferreira e prefeitura) observaram-se as menores temperaturas devido à presença de vegetação, que, neste horário, desempenhou papel importantíssimo na diminuição da temperatura.

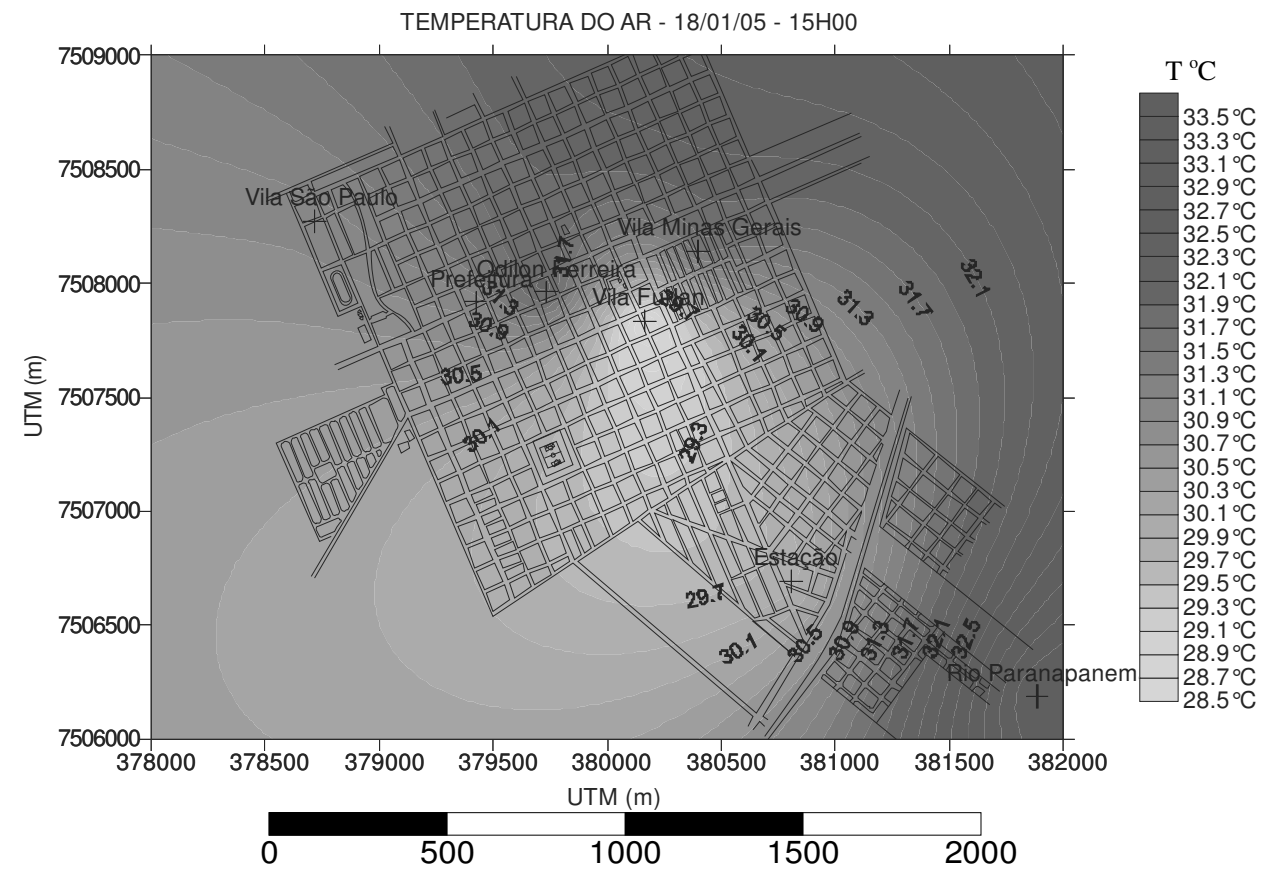

Figura 3: Isotermas às $15 \mathrm{~h}$ (padrão predominante no horário)

\section{Caracterização dos elementos climáticos às $21 \mathrm{~h}$}

Às 21h, as áreas com maiores quantidades de construções, ruas pavimentadas e pouca ou sem vegetação arbórea apresentaram temperaturas mais altas (Figura 4). Estas áreas são representadas pelos pontos Odilon 
Ferreira e Prefeitura. O ponto que apresentou as maiores temperaturas (Odilon Ferreira), possui alta densidade de construções, ruas pavimentadas e árvores de grande porte com copas que impedem a visão do céu e dificultam a dispersão do calor. O outro ponto (Prefeitura), também com temperaturas elevadas, é densamente construído, com menor densidade de arborização e mesmo ausência de vegetação.

Cabe salientar que, em alguns dias, especificamente 17, 21, 24 e 25, o ponto Vila São Paulo apresentou elevadas temperaturas, embora apresente construções esparsas, gramados e vegetação de grande porte em abundância. Esta elevação na temperatura pode ser atribuída à presença da Cerâmica Vera Cruz, que nestes dias estava com as suas fornalhas acesas desde o entardecer.

A maior amplitude térmica entre os pontos foi encontrada no dia 17/01, sendo de $4^{\circ} \mathrm{C}$. O ponto mais quente foi a Vila São Paulo. A temperatura do ar observada foi de $28^{\circ} \mathrm{C}$, com $90 \%$ de umidade relativa, vento de Leste, com velocidade de 3,4 a 5,2 m/s e céu totalmente coberto por nuvens.

No geral, no restante dos dias pesquisados, as amplitudes térmicas entre os pontos oscilaram entre $1,5^{\circ} \mathrm{C}$ e $2^{\circ} \mathrm{C}$. As amplitudes higrométricas ficaram entre $10 \%$ a $20 \%$, e os pontos Odilon Ferreira e Prefeitura apresentaram as maiores temperaturas e as menores taxas de umidade relativa. As magnitudes encontradas podem ser classificadas como sendo de fraca a moderada.

As menores temperaturas, na maioria dos dias pesquisados, foram observadas nos pontos Estação e Vila São Paulo, áreas que possuem, em comum, menor densidade de construções. Cabe salientar que, na Estação, as menores temperaturas podem ser atribuídas à inexistência de pavimentação nas ruas, associada à presença de vegetação e, na Vila São Paulo, a forte presença de vegetação, já que as ruas são pavimentadas.

No ambiente rural, as temperaturas mostraram-se em condições intermediárias (entre os pontos mais quentes e mais frios), devido à proximidade com o Rio Paranapanema. A umidade presente no ar permitiu situações de desconforto térmico, comuns em noites de verão, com umidade do ar relativamente elevada, em torno dos $90 \%$.

As condições térmicas e higrométricas encontradas às $21 \mathrm{~h}$ são fruto das modificações no balanço energético entre a cidade e o campo: há armazenamento de calor pelos materiais utilizados nas contruções (concreto e asfalto) que, mesmo após o anoitecer continuam emitindo calor para atmosfera, enquanto nas áreas com menor número de construções e presença de vegetação, ocorre um resfriamento mais rápido.

Um dos bairros mais planejados na cidade (construções bem espaçadas, arborização, gramados e áreas livres), teve interferência do calor antrogênico, devido ao calor emitido pelas fornalhas da Cerâmica Vera Cruz e pelo intenso tráfego de veículos na área central; isso maximizou o calor que estava sendo devolvido pelos materiais utilizados nas construções (concreto e asfalto) para a atmosfera urbana.

Este comportamento térmico e higrométrico perdurou durante a noite nas áreas com alta densidade de construções e teve influência nas temperaturas do dia seguinte. 


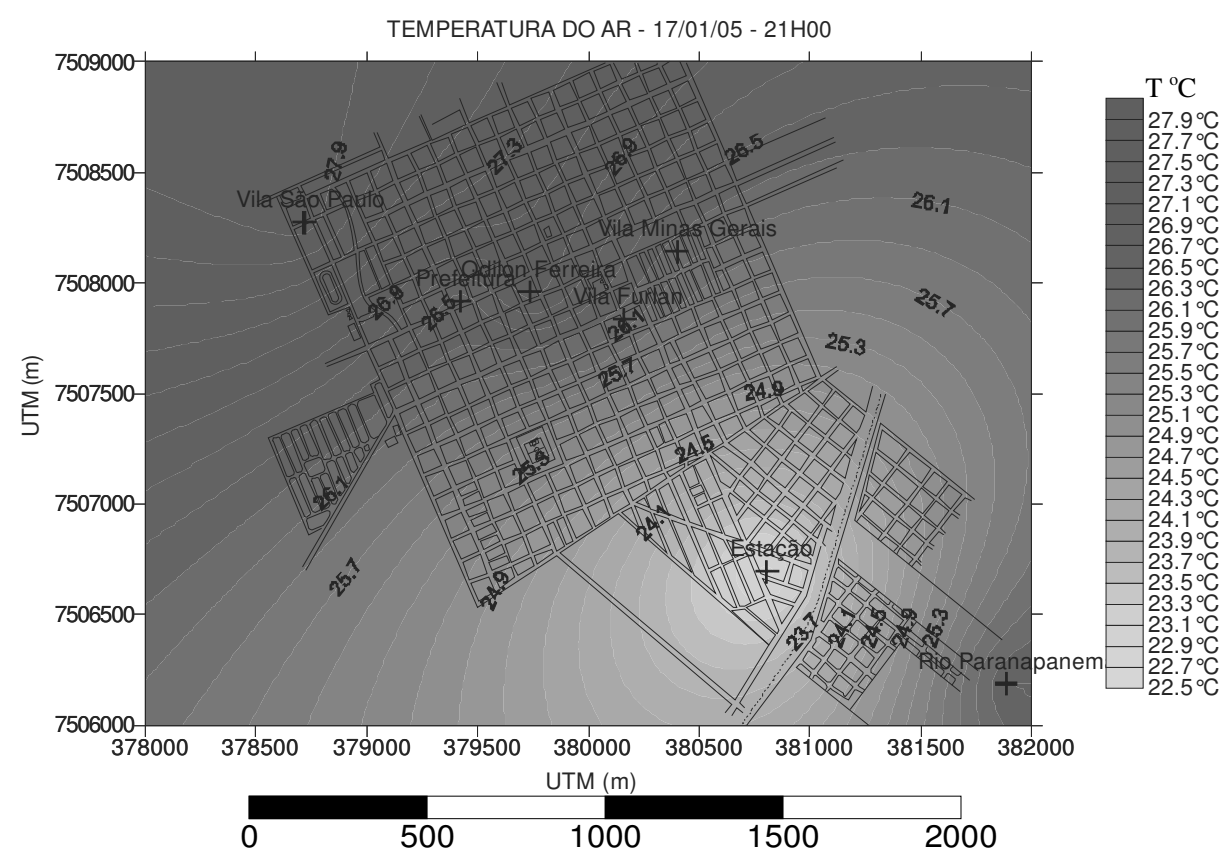

Figura 4: Isotermas às $21 \mathrm{~h}$ (padrão predominante no horário)

\section{CONSIDERAÇÕES FINAIS}

Nesta pesquisa, concluiu-se que Teodoro Sampaio apresenta características distintas quanto à formação de um clima urbano específico, principalmente nas magnitudes térmicas e higrométricas encontradas.

Ao final desta pesquisa, observou-se que, durante os dias representativos de verão, ficou comprovada a formação de ilhas de calor e de frescor. Quanto à magnitude do fenômeno, esta se diferenciou de acordo com o horário, local e sistema atmosférico atuantes.

Às $7 \mathrm{~h}$ e às $21 \mathrm{~h}$ têm-se a configuração de ilhas de calor (fraca a moderada) no meio urbano, fruto do armazenamento de calor nos materiais utilizados (concreto e asfalto) durante o dia, além da contribuição do calor antropogênico (fluxo de veículos e Cerâmica Vera Cruz).

Às $9 \mathrm{~h}$ e 15h, a área rural atingiu temperaturas mais elevadas, com magnitudes superiores às apresentadas no meio urbano. Este comportamento pode ser atribuído a grande quantidade de vegetação existente na cidade, que favoreceu a diminuição da temperatura e contribuiu para a formação de ilhas de frescor urbana.

Os sistemas atmosféricos tiveram significativa contribuição nos valores encontrados, principalmente no meio urbano. Anterior à passagem das Frentes Frias, houve a elevação da temperatura, maximizando, assim, a intensidade da ilha de calor. Com a passagem da Frente, a temperatura diminuiu, assim como as magnitudes encontradas.

Neste período de coleta de dados ficou comprovada a formação de ilhas de calor e de frescor. As ilhas de calor urbana se configuraram no inicio da manhã e após o entardecer. As ilhas de frescor urbana são mais evidentes a partir das $9 \mathrm{~h}$ e adquiriram maior intensidade às $15 \mathrm{~h}$. Quanto à magnitude do 
fenômeno, esta se diferenciou de acordo com o horário, local e sistema atmosférico atuantes.

O estudo demonstrou que uma cidade de pequeno porte como Teodoro Sampaio já apresenta características peculiares quanto a sua temperatura, comprovando que existem diferenças no balanço de radiação entre áreas mais edificadas e com pouca ou ausência de vegetação e áreas menos edificadas, com presença de vegetação. Assim, estas áreas se diferenciaram de acordo com o tipo de materiais da cobertura do solo.

O uso e a ocupação do solo são aspectos do planejamento urbanístico, que trata da forma como se organiza a cidade, segundo a aplicação de instrumentos legais de controle deste aspecto. Para isso, consideram-se diversos tipos de fatores que influem mais diretamente nesta questão, como a densidade populacional, a densidade das construções e a destinação da terra. Segundo Silva (1997) estes instrumentos legais são englobados por instituições e institutos jurídicos sob o conceito de zoneamento do solo, sendo um instrumento legal do poder público para controlar o uso da terra, as densidades de população, a localização, a dimensão das construções e seus usos específicos em prol do bem estar geral.

Nesta pesquisa, conclui-se que o uso e a ocupação do solo influenciaram nas condições térmicas, de maneira a apresentar valores de temperatura devido às configurações de densidade das edificações e presença de pavimentação nas ruas. Outro fator de suma importância é a presença da vegetação. A presença de áreas verdes tem o papel de diminuir a temperatura intra-urbana, através do processo de evapotranspiração realizado pelas plantas, que libera o calor através da perda de água, e não em forma de forma de radiação, como ocorre nas superfícies de asfalto e concreto.

Nesse sentido, o planejamento urbano adequado para Teodoro Sampaio contribuiria para o melhor gerenciamento dos componentes urbanos, pois, em uma cidade desordenada, esses usos desenvolvem-se de maneira misturada, com grande prejuízo para o bem estar da população. Assim, o planejamento urbano de Teodoro Sampaio deveria se ater à melhor ordenação do uso e ocupação e à implantação de áreas verdes, nos futuros bairros.

\section{REFERÊNCIAS}

AMORIM, M. C. C. T. O clima urbano de Presidente Prudente/SP. São Paulo, 2000. 374p. Tese (Doutorado em Geografia) - Faculdade de Filosofia, Letras e Ciências Humanas, Universidade de São Paulo.

BARRIOS, N.A.Z., SANT'ANNA NETO, J.L. A circulação atmosférica no extremo oeste paulista. Boletim Climatológico, Presidente Prudente, v.1, n.1, p.8-9, março 1996.

GARCÍA, F. F. Manual de Climatologia Aplicada. Clima, médio ambiente y aplicacíon. Madrid:Editorial Sínteses, 1996.

JACOBS, J. Morte e Vida de Grandes Cidades. Trad.Carlos S. Mendes Rosa. São Paulo: Martins Fontes, 2000. 
MENDONÇA, M. A dinâmica têmporo-espacial do clima subtropical na região conurbada de Florianópolis/SC. São Paulo, 2002. Tese (Doutorado em Geografia) - Faculdade de Filosofia, Letras e Ciências Humanas, Universidade de São Paulo.

MENDONÇA, F. Clima e planejamento urbano em Londrina. Clima Urbano. Org. Mendonça, F; Monteiro, C.A de F. São Paulo: Contexto, 2003.

MONTEIRO C. A. de F. Teoria e Clima Urbano. São Paulo: IGEOG/USP, 1976. 181p. (Série Teses e Monografias, 25).

MONTEIRO C. A. de F. Por um suporte teórico e prático para estimular estudos geográficos do clima urbano no Brasil. Geosul, Florianópolis, v.5, n.9, p.7-19, 1990a.

MONTEIRO C. A. de F. Adentrar a cidade para tomar-lhe a temperatura. Geosul, Florianópolis, v.5, n.9, p. 61-79, 1990b.

MONTEIRO C. A. de F. A cidade como processo derivador ambiental e estrutura geradora de um "clima urbano". Geosul, Florianópolis, v.5, n.9, p. 80-114, 1990c.

OKE, T.R. The energetic basis of the urban heat island. Quarterly Journal of the Royal Meteorological Society, v.108, n. 455, p.1-24, jan. 1982.

SEZERINO, M. L., MONTEIRO, C. A. F. O campo térmico na cidade de Florianópolis: primeiros experimentos. Geosul, Florianópolis, v.5, n.9, p. 20$60,1990$.

SILVA, J. A. da. Direito Urbanístico Brasileiro. 2 ed. rev. at. $2^{a}$ tiragem. São Paulo: Malheiros Editores, 1997. 